\title{
Crescimento, Esporulação e Virulência do Inóculo de Cercospora piaropi, Agente de Biocontrole do Aguapé*
}

\author{
Zilá R. de Ávila ${ }^{1 * *}$ \& Robinson A. Pitelli \\ 'Embrapa Recursos Genéticos e Biotecnologia, Cx. Postal 02372, CEP 70849-970, Brasília, DF, e-mail: zilavila@ hotmail.com; \\ ${ }_{2}^{2}$ Departamento de Biologia Aplicada a Agropecuária, Faculdade de Ciências Agrárias e Veterinárias de Jaboticabal, Unesp, \\ CEP 14884-900, Jaboticabal, SP, e-mail: pitelli@ fcav.unesp.br
}

(Aceito para publicação em 02/10/2003)

Autor para correspondência: Zilá R. de Ávila

ÁVILA, Z.R. \& PITELLI, R.A. Crescimento, esporulação e virulência do inóculo de Cercospora piaropi, agente de biocontrole do aguapé. Fitopatologia Brasileira 29:189-192. 2004.

\section{RESUMO}

O presente ensaio foi realizado com o objetivo de avaliar a produção de biomassa micelial bem como a esporulação de Cercospora piaropi, nos meios líquidos V8, ETD (Extrato de Tomate Diluído) e BD (Batata - Dextrose), em períodos de cultivo de 96, 120, 144 e 168 h, sob agitação constante. Adicionalmente foi avaliado o efeito de períodos de desidratação da biomassa micelial (24, 48, 72, 96 e 120 h) sobre a esporulação. Os inóculos obtidos foram avaliados quanto à severidade da doença em plantas de aguapé (Eichhornia crassipes). De acordo com os resultados, o meio ETD proporcionou maior crescimento micelial em relação aos meios BD e V8, destacando-se o período de 144 h de agitação. Entretanto, o meio V8 induziu esporulação superior do patógeno, quando cultivado por $120 \mathrm{~h}$. Os inóculos obtidos nos meios V8 e ETD causaram maiores valores de severidade da doença. O período de desidratação da biomassa micelial a partir de $72 \mathrm{~h}$ favoreceu maior produção de conídios. Não houve efeito do período de desidratação sobre a severidade da doença.

Palavras-chave adicionais: meios de cultura, período de cultivo, crescimento micelial, planta invasora, Eichhornia crassipes.

\section{ABSTRACT}

Growth, sporulation and virulence of Cercospora piaropi inoculum, biocontrol agent of water hyacinth

The current assay was carried out to evaluate the mycelial biomass production and sporulation of Cercospora piaropi in V8, ETD and BD liquid media at incubation periods of 96, 120, 144, and $168 \mathrm{~h}$, under constant agitation. Additionally, the effect of dehydration periods on the sporulation of mycelial biomass at 24 , 48, 72, 96 and $120 \mathrm{~h}$ was evaluated. The obtained inocula were evaluated according to the severity of the disease on water hyacinth
(Eichhornia crassipes) plants. In accordance with the results, the ETD media yielded more mycelial growth than the BD and V8 media, especially after $144 \mathrm{~h}$ of agitation. However, the V8 medium induced a higher pathogen sporulation rate, when cultivated for up to $120 \mathrm{~h}$. The obtained inocula produced in V8 and ETD media caused higher values of disease severity. The dehydration period of the mycelial biomass from $72 \mathrm{~h}$ was favorable for a higher conidial production. The dehydration period has no effect on disease severity.
O aguapé [Eichhornia crassipes (Mart.) SolmsLaubach] é considerado uma das macrófitas mais problemáticas em corpos d' água nos trópicos e subtrópicos, apresentando elevado potencial de crescimento. Altas densidades desta planta prejudicam o ecossistema aquático, causando grande variedade de problemas, tais como: redução do fluxo de água em canais, represas e rios, dificuldade para navegação e pesca, interferência no funcionamento de bombas de irrigação, abrigo para organismos vetores de doenças para o homem e animais e redução da concentração média de oxigênio dissolvido na coluna d' água (Pitelli 2000; Shabana et al., 2001). Ocorre também redução na geração de energia elétrica, pois interfere no funcionamento das turbinas das usinas hidrelétricas (OrachMeza, 1996). Estes problemas contribuem para que vários esforços sejam conduzidos no sentido de minimizar os efeitos

\footnotetext{
?Parte da Tese de Doutorado do primeiro autor. Universidade Estadual Paulista. Jaboticabal, SP (2002).

**Bolsista da CAPES
}

drásticos desta planta por meio de controle com utilização dos produtos químicos, colheita mecânica e agentes de controle biológico (Gelmini, 1995; Charudattan, 2001).

O controle biológico de plantas daninhas com a utilização de patógenos de plantas tem sido uma alternativa pesquisada em várias partes do mundo (Mello et al., 2000; Charudattan, 2001). Especificamente no caso do aguapé, pode ser citado o fungo Cercospora piaropi Tharp. Este patógeno foi avaliado por vários anos nos Estados Unidos, apresentando resultados altamente promissores (Conway et al, 1976). A sua alta especificidade de hospedeiros tem sido o mais importante fator para considerá-lo como candidato a bio-herbicida (Freeman \& Charudattan, 1984; Martinez \& Gutierrez, 2001). Um isolado de $C$. piaropi foi selecionado, entre vários fitopatógenos, em coleta realizada pela equipe do NEPEAM/ UNESP e da Embrapa Recursos Genéticos e Biotecnologia, para utilização como possível agente potencial para o controle do aguapé. Uma das características do gênero Cercospora é o 


\section{Z.R. Ávila \& R.A. Pitelli}

crescimento lento e a escassez de esporulação em meios artificiais (Del Peloso et al., 1989). Na literatura são encontrados vários relatos sobre a determinação de condições de cultivo para o crescimento e esporulação de Cercospora spp. onde são avaliadas variáveis como composição do meio de cultura, fotoperíodo, temperatura, período de incubação, $\mathrm{pH}$ e outros, obtendo-se resultados variáveis, pois as interações são múltiplas e pouco conhecidas (Silva et al, 1988).

Considerando que no desenvolvimento de um bioherbicida, grande atenção é dada para o estabelecimento de condições ótimas para o desenvolvimento da doença, a fim de se aprimorar o uso e a qualidade do agente causal (Jackson $e t$ al., 1996; Ávila et al., 2000), o objetivo deste trabalho foi o de contribuir para elaboração de um protocolo preliminar visando à produção massal de inóculo virulento de $C$. piaropi. Para tal, testaram-se meios de cultura, períodos de crescimento, e períodos de desidratação do micélio. Verificou-se também a virulência do inóculo obtido nas diferentes condições testadas por meio de inoculações em plantas de aguapé.

Efeito de composições de meios de cultura e períodos de cultivo sobre o crescimento, esporulação e virulência de C. piaropi em plantas de aguapé

Foram avaliados três meios de cultura: BD (extrato de $200 \mathrm{~g}$ de batata $+20 \mathrm{~g}$ de dextrose/l), ETD (Extrato de Tomate Diluído, marca Sopurê Arisco, $200 \mathrm{ml} / \mathrm{l}$ ) e suco V8, marca "Campbell Soup Co." (200 ml/l). O pH dos meios foi ajustado para 5.5. Para frascos com capacidade de $250 \mathrm{ml}$ foram transferidos $75 \mathrm{ml}$ de cada meio, sendo posteriormente esterilizados a $120^{\circ} \mathrm{C}$ por $20 \mathrm{~min}$. Dois discos de $5 \mathrm{~mm}$ de diâmetro, foram retirados de colônias de $C$. piaropi cultivado por dez dias em meio BDA, e adicionados aos meios de cultura. Estes frascos foram mantidos em agitador mecânico com rotação de 150 rpm, à temperatura de $25{ }^{\circ} \mathrm{C}$, na ausência de luz. Foram avaliados quatro períodos de agitação contínua: 96, 120, 144 e $168 \mathrm{~h}$. Após estes períodos, a biomassa micelial obtida foi filtrada em peneira com diâmetro de malha de $0,212 \mathrm{~mm}$ e, com auxílio de uma espátula, fez-se pressão sobre a mesma para retirada de todo o excesso de líquido. Posteriormente, a biomassa micelial foi colocada em papéis de filtro dispostos em bandejas, em sala para incubação de fungos, mantendo-se a temperatura a $25{ }^{\circ} \mathrm{C}$ e umidade relativa entre $50-70 \%$, na ausência de luz. Após $72 \mathrm{~h}$ de secagem, avaliou-se a produção micelial através da pesagem da biomassa. A concentração de conídios foi determinada com auxílio de câmara de Neubauer. A suspensão, para a contagem de conídios, foi preparada com $20 \mathrm{ml}$ de água destilada contendo Tween-20 a $0,02 \%$ adicionada sobre a biomassa micelial em Becker, sendo este agitado manualmente para a separação dos conídios da biomassa. Foi utilizado o delineamento experimental inteiramente casualizado em esquema fatorial com cinco repetições, sendo cada repetição representada por um frasco.

A fim de avaliar o efeito das composições de meios de cultura e dos períodos de cultivo sobre a virulência do patógeno, plantas de aguapé foram inoculadas com suspensão micelial, preparada a partir da trituração do micélio em solução de água destilada e Tween-20 (0,02\%), imediatamente após a filtragem da biomassa anteriormente descrita, nesta fase não se constatou a presença de conídios. Utilizaram-se $2 \mathrm{~g}$ de micélio fresco por litro de suspensão. Esta suspensão foi pulverizada sobre plantas de aguapé com três folhas, até o ponto de escorrimento da calda, sendo posteriormente mantidas sob câmara úmida por $18 \mathrm{~h}$ em casa de vegetação. Após o período de 60 dias efetuou-se a avaliação da doença utilizando-se escala de notas de severidade do sintoma, descrita por Freeman \& Charudattan (1984), variando de 0 (sem sintomas) a 9 (folha morta), considerando o desenvolvimento de lesões necróticas observadas nas folhas que receberam a aplicação do fungo, denominada severidade nas folhas inoculadas (SFI) e na planta toda, incluindo as folhas emitidas após a inoculação, representando a severidade na planta toda (SPT). A redução do crescimento da planta foi avaliada pela contagem do número total de folhas emitidas e o cálculo da fórmula: $\mathrm{RC}=[($ Test Trat)/ Test] $\times 100$, onde RC = Redução do crescimento; Test = Média do número de folhas da testemunha e Trat = número de folhas do tratamento por repetição. Foi utilizado o delineamento experimental inteiramente casualizado, com sete repetições, sendo a repetição representada por um vaso com uma planta.

Efeito de períodos de desidratação da biomassa micelial sobre a produção e virulência de conídios de $C$. piaropi

Neste ensaio, o patógeno foi cultivado em meio V8 sob agitação contínua por $120 \mathrm{~h}$. Os procedimentos para o preparo e inoculação do meio de cultura, filtragem da biomassa micelial, condições de incubação e determinação da concentração de conídios, foram os mesmos adotados no ensaio anterior. Após o crescimento da biomassa micelial, esta foi mantida em sala para incubação de fungos a temperatura de $25{ }^{\circ} \mathrm{C}$ e UR entre 50 a $70 \%$ para a desidratação natural durante os seguintes períodos: 24, 48, 72, 96 e $120 \mathrm{~h}$. O ensaio foi disposto no delineamento experimental inteiramente casualizado com seis repetições por tratamento, sendo a repetição constituída por um frasco.

Para avaliar a virulência dos conídios obtidos, foi utilizada a concentração de $1,6 \times 10^{5}$ conídios $/ \mathrm{ml}$, em água destilada acrescida de Tween $20(0,02 \%)$ e como testemunhas, plantas inoculadas somente com micélio fresco $(2 \mathrm{~g} / \mathrm{l})$ e sem inoculação, adotando-se procedimento de inoculação e avaliação semelhantes ao do ensaio anterior. Foram utilizadas quatro repetições em delineamento inteiramente casualizado, sendo a repetição constituída de um vaso com uma planta.

Os dados dos tratamentos foram submetidos à análise de variância e as médias comparadas pelo teste de Tukey a $5 \%$ de probabilidade.

Os resultados indicaram que o cultivo do fungo em meio ETD sob $144 \mathrm{~h}$ de agitação proporcionou maior produção micelial (Figura 1A). Entretanto, para esporulação do fungo, o meio V8 foi o mais eficiente especialmente no período de cultivo de $120 \mathrm{~h}$ (Figura 1B). É importante observar que após este período, houve redução do número de conídios produzidos. Este comportamento também foi relatado para outras 
Crescimento, esporulação e virulência do inóculo de Cercospora piapori...

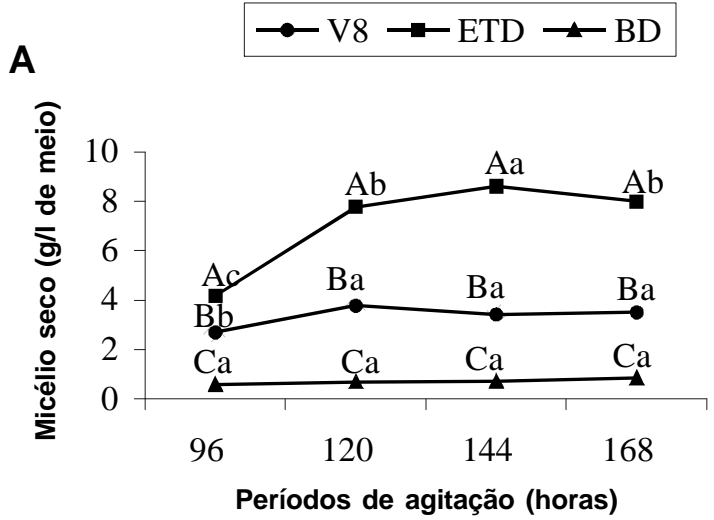

B

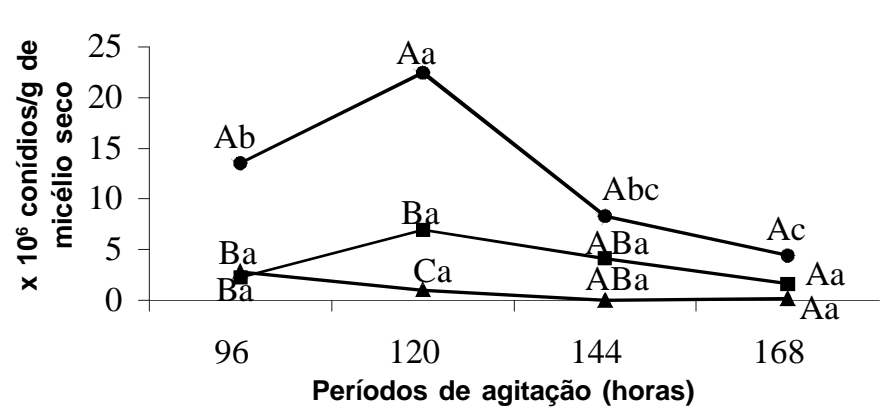

FIG. 1 - Efeito da composição de meios de cultura e períodos de agitação sobre o crescimento de Cercospora piaropi. A) produção de biomassa micelial; B) produção de conídios. Médias seguidas de mesma letra não diferem estatisticamente entre si pelo teste de Tukey a $5 \%$. Letras minúsculas comparam as médias no sentido horizontal e maiúsculas no sentido vertical.

espécies (Silva et al., 1988). A redução da esporulação no decorrer do tempo pode ser explicada devido à exaustão do meio exercendo efeito sobre o crescimento e fertilidade das hifas produzidas (Carlile \& Watkinson, 1996). Apesar do meio ETD ter proporcionado maior produção micelial, não resultou em maior produção de conídios. Para alguns fungos, as condições para esporulação e crescimento vegetativo freqüentemente diferem (Carlile \& Watkinson, 1996; Sanderson \& Jeffers 2001). Os períodos de cultivo não afetaram a virulência do patógeno, entretanto o mesmo não foi observado para as composições de meios de cultura. Os inóculos obtidos nos meios V8 e ETD proporcionaram maiores valores de severidade da doença observada nas folhas inoculadas (SFI) e na planta toda (SPT), independente do período de agitação (Figura 2A). Para a porcentagem de folhas infetadas não houve diferença estatística entre os tratamentos. Houve redução do crescimento da planta ocasionada pelos inóculos produzidos nos três meios avaliados, entretanto o fungo cultivado no meio V8 proporcionou maior redução de crescimento (Figura 2B). A influência do meio de cultura sobre a virulência de diversos fitopatógenos também foi constatada por Masangkay et al. 2000. Provavelmente a produção ou ausência de certos metabólitos nos diferentes meios pode ter ocasionado a diferença encontrada no presente experimento. Os resultados
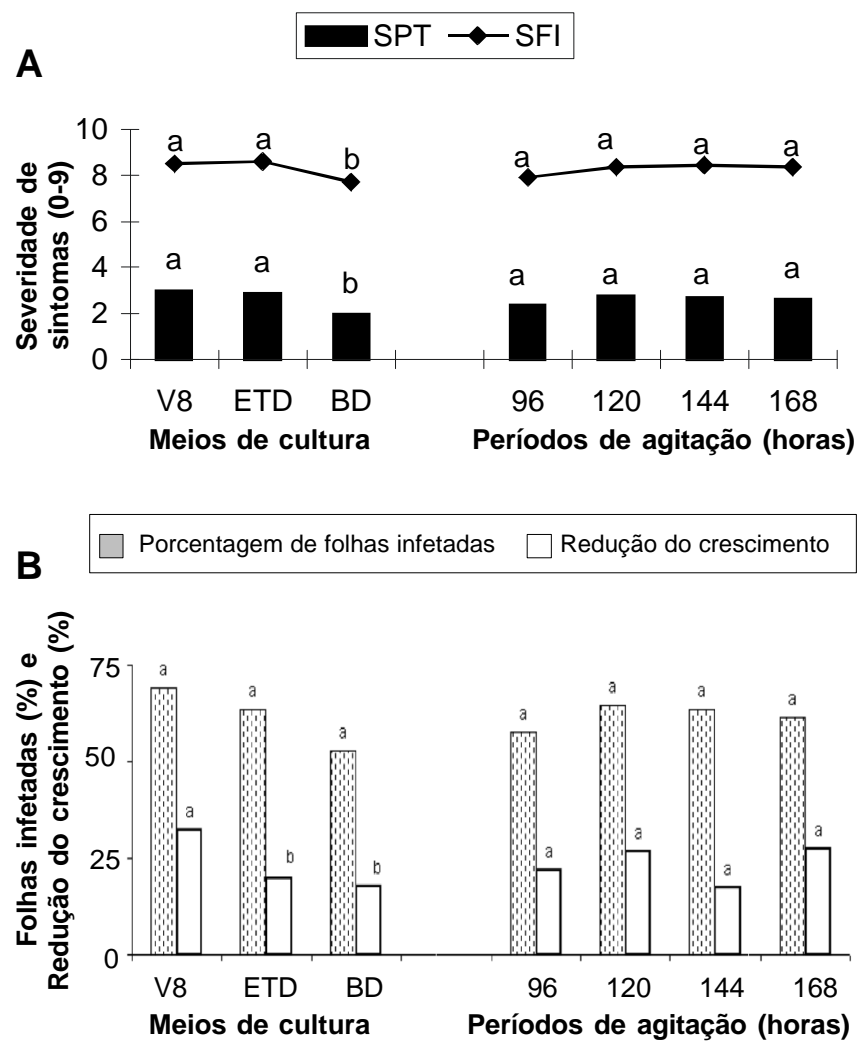

FIG. 2 - Efeito da composição de meios de cultura e períodos de agitação sobre a virulência de Cercospora piaropi. A)SPT= severidade planta toda (0-9); SFI = severidade em folhas inoculadas (0-9); B)\%FI= Porcentagem de folhas infetadas e RC\%= Redução do crescimento. Médias seguidas de mesma letra não diferem estatisticamente entre si pelo teste de Tukey a $5 \%$.

obtidos neste estudo indicam que o crescimento micelial, e a esporulação de $C$. piaropi são consideravelmente influenciados pela composição do meio de cultura e período de cultivo. Considerando a virulência como o atributo mais importante para a produção do inóculo, o meio V8 mostrou-se como a composição mais adequada para obtenção de propágulo altamente infetivo.

A partir de $24 \mathrm{~h}$ de desidratação da biomassa micelial ocorreu esporulação em nível considerável $\left(2,73 \times 10^{6}\right.$ conídios/g de micélio), havendo um acréscimo na produção de conídios à medida que foi prolongado o número de horas de desidratação, estabilizando-se a partir do período de $72 \mathrm{~h}$ (Figura 3A).

De modo geral, o período de desidratação da biomassa micelial, não afetou a virulência dos conídios (Figura 3B). Observou-se redução do crescimento da planta em todos tratamentos, porém não diferiram estatisticamente entre si. $\mathrm{O}$ mesmo foi observado em relação à porcentagem de folhas infetadas (Figura 3B).

Neste ensaio, todas composições dos meios de cultivo favoreceram o desempenho do fungo apesar de diferirem entre si, possibilitando assim, alternativas de produção de inóculo. Os meios V8 e ETD utilizados neste estudo foram obtidos em 

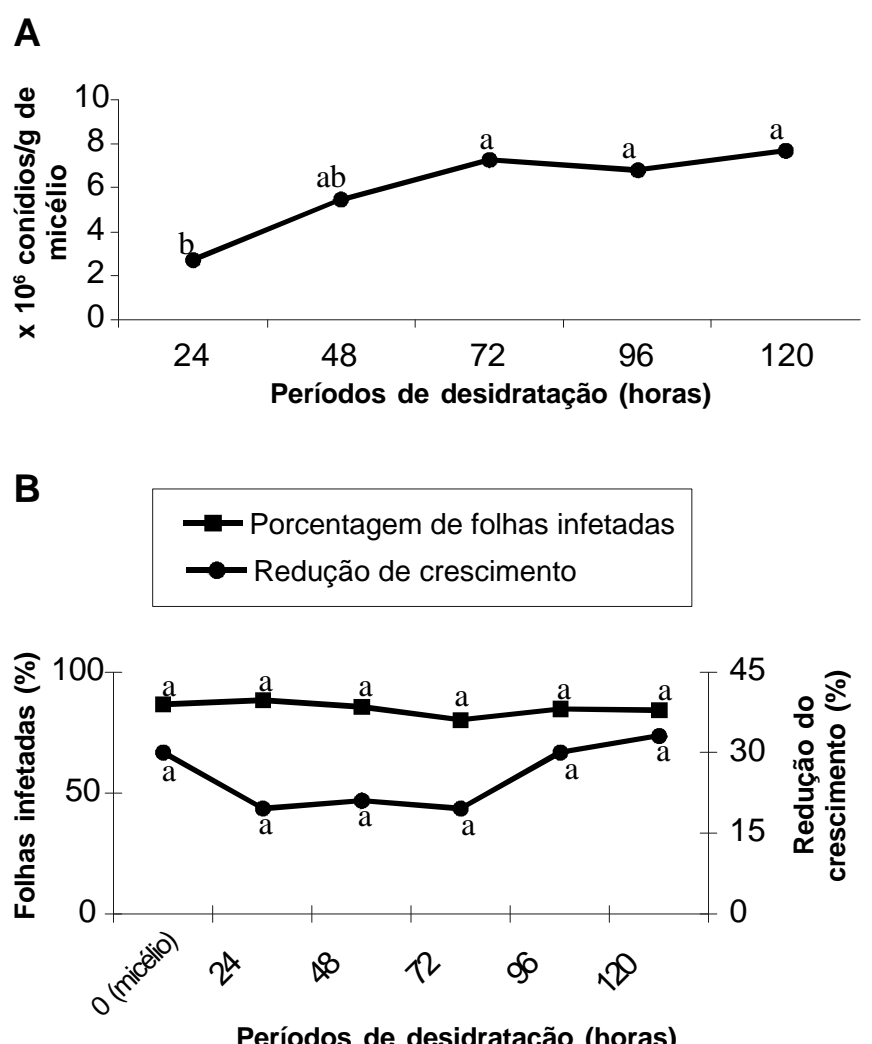

FIG. 3 - Efeito do período de desidratação da biomassa micelial sobre a esporulação e virulência de conídios de Cercospora piaropi. A) Esporulação; B)\%FI = Porcentagem de folhas infetadas; $\mathrm{RC} \%=$ redução do crescimento. Médias seguidas de mesma letra não diferem estatisticamente entre si pelo teste de Tukey a $5 \%$.

comércio, entretanto é possível produzi-los em laboratório, o que contribuirá para redução do custo de sua produção (Ávila et al., 2000).

Segundo Jackson et al. (1996), os métodos para produção de agentes bio-herbicidas devem ser de baixo custo, permitindo a obtenção de altas concentrações de inóculo altamente viável e efetivo. Os resultados apresentados neste trabalho indicam que o cultivo de C. piaropi em meio V8 durante $120 \mathrm{~h}$ de agitação e desidratação da biomassa micelial para esporulação por um período mínimo $72 \mathrm{~h}$, favorecem a produção satisfatória de inóculo efetivo.

\section{REFERÊNCIAS BIBLIOGRÁFICAS}

ÁVILA, Z.R., MELLO, S.C.M., RIBEIRO, Z.M.A. \& FONTES, E.M.G. Produção de inóculo de Alternaria cassiae. Pesquisa
Agropecuária Brasileira 35:533-541. 2000.

CARLILE, M.J. \& WATKINSON, S.C. The fungi. Academic PressLimited. San Diego. 482p. 1996.

CHARUDATTAN, R. Biological Control of water hyacinth by using pathogens: opportunites, challenges, and recent developments. In: Meeting of the global working group for the biological and integrated control of water hyacinth, 2., 2000, Beijing, China. Proceedings... Austrália: ACIAR, 2001, pp.21-28.

CONWAY, K.E. Cercospora rodmanii, a new pathogen of water hyacinth with biological control potential. Canadian Journal of Botany 54:1079-1083. 1976.

FREEMAN, T.E. \& CHARUDATTAN, R. Cercospora rodmanii Conway a biocontrol agent for waterhyacinth. Gainesville. University of Florida. Bulletin technicall, 842. 1984.

GELMINI, G.A. Controle químico do aguapé (Eichhornia crassipes (Mart.) Solms) e da alface d'água (Pistia stratiotes L.). (Dissertação de mestrado). Piracicaba. Escola Superior de Agricultura Luiz de Queiroz. 1995

JACKSON, M.A., SCHISLER, D.A., SLININGER, P.J., BOYETTE, C.D., SILMAN, R.W. \& BOTHAST, R.J. Fermentation strategies for improving the fitness of a bioherbicide. Weed Technology 10:645-650. 1996

MARTINEZ, J.M. \& GUTIERREZ, L.E. Host range of Cercospora piaropi and Acremonium zonatum, potential fungal biocontrol agents for waterhyacinth in Mexico. Phytoparasitica 19:175-177. 2001.

MASANGKAY, R.F., PAULITZ, T.C., HALLET, S.G. \& WATSON, A.K. Characterization of sporulation of Alternaria alternata $\mathrm{f}$. sp. sphenocleae. Biocontrol Science and Technology 10:385-397. 2000.

MELlO, S.C.M., ÁVILA, Z.R., FONTES, E.M.G., RIBEIRO, Z.M.A. \& PAIS, J.S.O. Processo de produção do fungo Alternaria cassiae para biocontrole de fedegoso (Senna obtusifolia). Brasília:Embrapa Recursos Genéticos e Biotecnologia. Boletim de pesquisa, 18. 2000.

PITELLI, R.A. Aquatic weeds problems in hydropower systems. Third International Weed Science Congress-IWSC. Foz do Iguaçu. p.216. 2000.

SANDERSON, P.G. \& JEFFERS, S.N. Vegetative growth and conidium production by Monilinia oxycocci in vitro. Mycologia 93:9-16. 2001.

SHABANA, Y.M., ELWAKIL, M.A. \& CHARUDATTAN, R. Biological control of water hyacinth by mycoherbicide in Egypt. In: Proceedings, 2 Meeting of the global working group for the biological and integrated control of water hyacinth, 2000, Beijing, China. Austrália:ACIAR, 2001, pp.53-56.

SILVA, M.F., CAVALCANTI, M.A., POROCA, D.M. \& LIMA, D.M. Cultivo e esporulação de Cercospora caribaea e C. henningsii, agentes causais de manchas foliares em mandioca. Fitopatologia Brasileira 13:54-58. 1988. 